\title{
Evaluation of Water Quality in Middle and Lower Yangtze River of China
}

\author{
Yanbin Yang ${ }^{1}$ \\ ${ }^{1}$ Jiangsu Tianyi High School, Erquan Road, Wuxi, Jiangsu, China
}

\begin{abstract}
The water resource is the basic natural resource and one of the controlling factors of the ecological environment. However, for China with extensive economic growth and high population pressure, deterioration of water quality has been a very serious problem. This research will focus on five main provinces along the Yangtze River, one of the richest and most economically developed areas in China. The data of lakes in five provinces is mainly from China Lake Scientific Database and the study chooses and analyzes four elements of the lake: nitrogen content, phosphorus content, dissolved oxygen content, and $\mathrm{pH}$ value. These four elements represent water quality or reflect the source of pollution. By R studio, both the ANOVA test and regression equation are used to indicate four elements' relationship among each other in the whole five provinces and each province's water quality and use condition. Jiangsu's average dissolved oxygen content is the highest among the five provinces and is supposed to have the highest water quality because of the strong self-purification ability of water. However, since it also owns the most developed industry seen from data of the number of industrial enterprise and industrial wastewater, lakes in Jiangsu have the highest average nitrogen and phosphorus content. Anhui has low dissolved oxygen content which can harm the production in the fishery. The $\mathrm{pH}$ value of lakes in Jiangxi is much lower than that of lakes in other provinces. Jiangxi province suffers from acid rain all year- round, which causes the acidification of groundwater and surface lakes.
\end{abstract}

\section{Introduction}

In recent years, with the emergence of a series of environmental problems such as global warming, the deterioration of water quality has been paid more and more attention from the public. The water resource is the basic natural resource and one of the controlling factors of the ecological environment; it has increasingly affected the global environment and development ${ }^{1}$. To be specific, for China, a great country of about 1.4 billion people, deterioration of water quality is a serious problem: more than $40 \%$ of its rivers are severely polluted, $80 \%$ of its lakes suffer from eutrophication, and about 300 million rural residents lack access to safe drinking water ${ }^{2}$. If we fail to deal with this problem in a timely and effective manner, water shortage and poor water quality are interacting with each other and threatening China's food industry, economic development, and quality of life ${ }^{3}$.

To solve the water pollution problem, China started water quality management in the 1970s, which slowed down the trend of a rapid deterioration of water quality to a certain extent. However, facing extensive economic growth and the huge population pressure, it is difficult for China to fundamentally improve the water environment quality, and its measures taken to control pollution are limited ${ }^{4}$. The Yangtze river, one of the most important rivers in China, has been proved to suffer from the destruction of organic pollutants and the deterioration of the ecosystem ${ }^{5}$. To understand and analyze these sources of pollution and their impacts, this study will focus on five main developed provinces in the middle and lower ranches of the Yangtze River. Yangtze river belt's major industries, the scale of important industrial products, the population of cities along the river, and the throughput of ports have all been among the forefront of the world's major inland river economic belt. As a result, these five provinces are in one of the regions with the strongest comprehensive strength and the largest strategic support in China ${ }^{6}$. Additionally, these five provinces along the Yangtze river have abundant water resources and the natural water system of the Yangtze River and its artificial canals make this area the densest river network in China ${ }^{7}$. Therefore, the analysis of water quality in these five provinces along the Yangtze river is authoritative and typical.

\section{Materials and Methods}

\subsection{Scope of the study}

The middle and lower reaches of the Yangtze river are located in central and eastern China, stretching eastward from the Wushan mountain. It has the most abundant water resources in China and the most concentrated freshwater lakes in the country. This work will focus on 
the water quality analysis of the lakes in five main provinces in the middle and lower reaches of the Yangtze river -- Anhui, Hubei, Hunan, Jiangsu, and Jiangxi.

\subsection{Data sources}

(1) This work chooses China Lake Scientific Database because it is one of the most comprehensive databases of lake data in China's provinces and has sufficient authority ${ }^{8}$. It was built by Nanjing Institute of Geography and Limnology and Chinese Academy of Sciences, one of the most authoritative academic organizations in China. It uses data resources mining and other technical measures to realize the organic integration of lake scientific data resources. The characteristics of lakes in different provinces are reflected mainly by the measurement of various trace elements such as nitrogen, phosphorus, and dissolved oxygen. Also, the $\mathrm{pH}$ value, the lake's water temperature, and weather on that day are included in the measurement. All of these measurements of elements characterize the lakes' condition. To be specific, the nitrogen in water mainly comes from the metabolism and corruption of organisms, the discharge of industrial wastewater, domestic sewage, the loss of nitrogen fertilizer. Phosphorus is the basic element in the synthesis of microorganisms such as algae and represents the reproduction of microorganisms ${ }^{9}$. A $\mathrm{pH}$ value means the standard for measuring the degree of acid and alkali in solution. Dissolved oxygen content is a measure of the self-purification capacity of a body of water ${ }^{8}$. The phosphorus content can reflect the eutrophication of the water environment to some extent.

(2) Lake microelement data from the five provinces were measured from 2008 to 2009. Compared with other databases, this database is relatively comprehensive since it covers the majority of the lakes in five provinces. Other databases are either within one province narrowly or broadly without detailed microelement measurement.

\subsection{Statistical analysis}

This study compared and analyzed the data of lakes in five provinces, by using Microsoft Excel and R studio, a programming language mainly for statistical analysis, mapping, and data mining. Data from the five provinces are collected to construct a representative picture of water quality in the middle and lower reaches of the Yangtze River. Then the lake data from five provinces are compared to each other to understand the differences in lake water quality. This study uses the analysis of variance (ANOVA) tests and regression to analyze the data. ANOVA, which developed by statistician Ronald Fisher, is a statistical model used to analyze the differences of the means among the groups in a sample. Regression analysis is a statistical method used in finance, investing, and other disciplines that attempt to determine the strength and character of the relationship between one dependent variable and a series of other variables ${ }^{11}$.

\section{Results of statistic analysis}

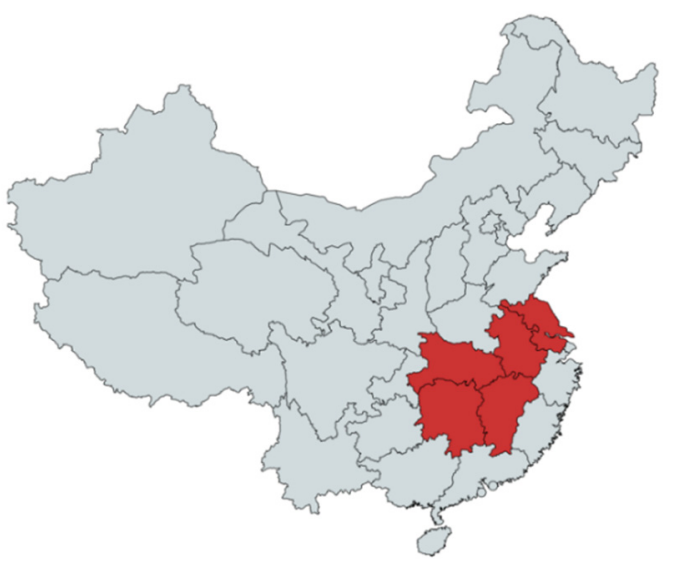

Fig. 1. The map of the five provinces (highlighted in red) included in our study. The five provinces are Anhui, Jiangxi, Jiangsu, Hubei, Hunan.

The mainstream of the Yangtze river crosses eleven provinces and this study focuses on five main typical provinces of them which represent the majority of the cases. The figure shows that five provinces along the Yangtze River. They are Anhui, Jiangxi, Jiangsu, Hubei, and Hunan provinces. The total area of these five provinces is 811,449 square kilometers $12-16$. These five provinces are located at the lower ranch of the Yangtze river close to the sea which can facilitate transportation for trading products.

Table 1. Number of lakes and data included in the study for the five provinces in the Lower Ranch of Yangtze River.

\begin{tabular}{|c|c|c|}
\hline Province & Number of lakes & Number of data \\
\hline Hubei & 23 & 86 \\
\hline Hunan & 8 & 52 \\
\hline Jiangxi & 7 & 69 \\
\hline Jiangsu & 9 & 81 \\
\hline Anhui & 8 & 50 \\
\hline
\end{tabular}

Table 1 indicates the total number of lakes sampled and analyzed for each province in this study, and the amount of data obtained from the analysis and measurement. They are separately shown as "number of lakes" and "number of data". Water quality data could be collected at multiple sites and different times in a lake, thus multiple data can be obtained from one lake. The various measurements of water quality of the lake represent the average situation of the lake and avoid bias from using a single data point. 


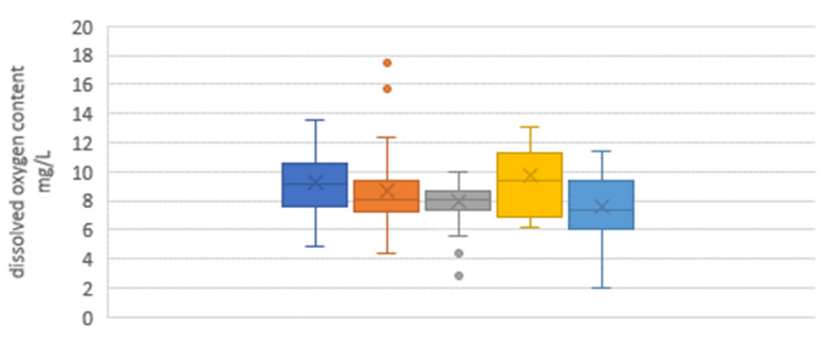

$\square$ Hubei $\square$ Hunan $\square$ Jiangxi $\square$ Jiangsu $\square$ Anhui

Fig. 2. Dissolved oxygen content in the lakes of the five provinces.

Figure 2-5 show the ranges of chemical contents and $\mathrm{pH}$ value in water resources in five provinces. Figure 2 presents dissolved oxygen content in lakes in five provinces. Average dissolved oxygen content in lakes of Jiangsu is $9.802 \mathrm{mg} / \mathrm{L}$, the highest one among five provinces. It means the average ability to degradation of all kinds of pollutants in the water of lakes in Jiangsu is the best among five provinces' lakes in some ways. Additionally, half of the lakes in Anhui's dissolved oxygen content and its average content are the lowest. This means the water quality of lakes in Anhui lags behind that of other provinces. According to the research of typical lakes in Anhui, the fishery resources of Chaohu Lake in Anhui province are decreasing year by year partly because of the decrease of dissolved oxygen in the lake. 17 This phenomenon is representative convincing evidence of how dissolved oxygen content influences the water ecosystem. According to the ANOVA test, the average dissolved oxygen contents of the five provinces are at the same level.

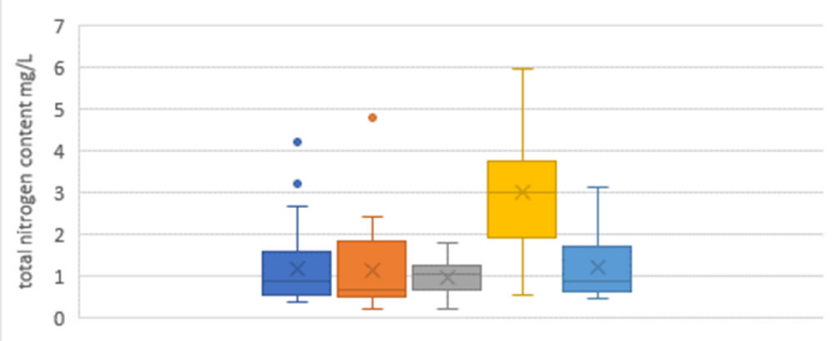

$\square$ Hubei $\square$ Hunan $\square$ Jiangxi $\square$ Jiangsu $\square$ Anhui

Fig. 3. Total nitrogen content in the lakes of the five provinces.

Figure 3 presents total nitrogen content in lakes in five provinces. Four provinces, including Hubei, Hunan, Jiangxi and Anhui, their nitrogen contents are at the same level according to the ANOVA test. But the value of Jiangsu is much higher than others. The average nitrogen content of lakes in Jiangsu is about $0.18 \mathrm{mg} / \mathrm{L}$ higher than the average of the other provinces. The excessive nitrogen content in lakes in Jiangsu causes eutrophication which can worsen the water quality and affect the growth and reproduction of aquatic organisms. Considering that nitrogen content of lakes in in Jiangsu is abnormally high, the reason for excessive nitrogen is mainly associated with human activity. Some normal changes in nature such as metabolism and spoilage of organisms have a weak effect on nitrogen content. In 2007 and 2008, Jiangsu ranked first in the discharge of industrial sewage among the five provinces. It discharged 268,762 and 259,999 million tons of industrial wastewater in 2007 and 2008, respectively. Furthermore, in 2007 and 2008, Jiangsu owned the most industrial enterprise above designated size in five provinces 18 (annual main business income of RMB 20 million or more of all industrial enterprises). As a result, all of these result in that Jiangsu is advanced development in industry but lacks awareness of environmental protection.

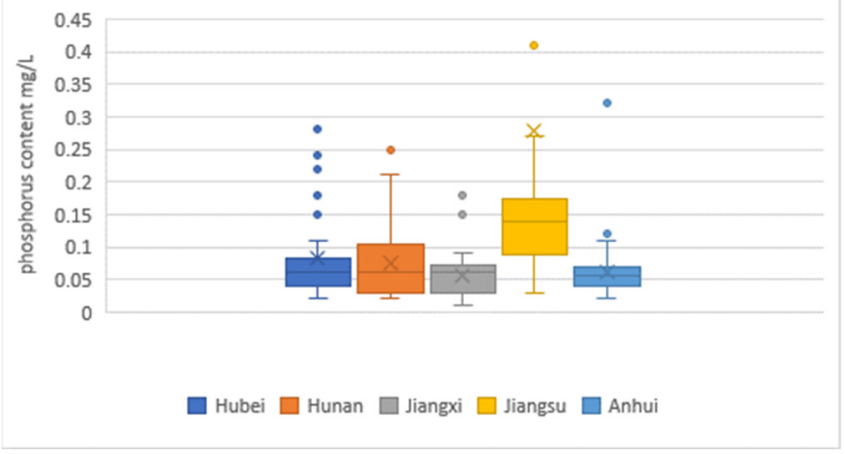

Fig. 4. phosphorus content in the five provinces.

Figure 4 presents the phosphorus content in the five provinces. According to the ANOVA test, the lakes in Jiangsu are significantly different from the other provinces in phosphorus content. The average phosphorus in Jiangsu is 3.1 times the average phosphorus content of other lakes. Phosphorus content is also an important trigger to algal boom like nitrogen. When it is above 0.01 $0.02 \mathrm{ppm}$, it indicates eutrophication. The value of Jiangsu is above the standard and facts in 2007 and 2008 prove it. In June 2007, the Taihu Lake cyanobacteria bloom, a few dozen centimeters thick cyanobacteria cover a large area of water. According to statistics released by the authority in Wuxi, one of the most important and famous cities in Jiangsu, the water quality of Wuxi's water plants, which account for $70 \%$ of the city's water supply, was contaminated 19 .

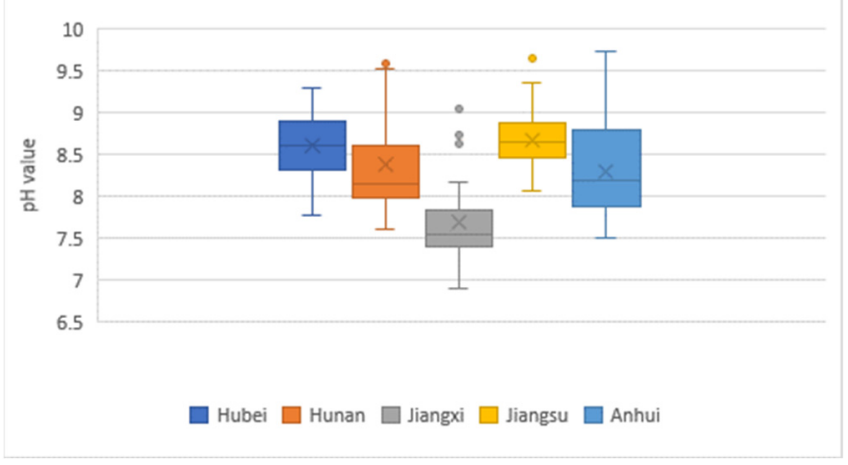

Fig. 5. the $\mathrm{pH}$ value in the five provinces. 
Figure 5 presents the $\mathrm{pH}$ value in the five provinces. According to the ANOVA test, four provinces except Jiangxi have similar $\mathrm{pH}$ value on average. The average $\mathrm{pH}$ values of lakes in Jiangsu is the highest but is only slightly higher than the average value in the other three provinces. However, the $\mathrm{pH}$ value of lakes in Jiangxi is about $11.7 \%$ less than the average of other lakes. The group with the highest $\mathrm{pH}$ in Jiangxi lakes reached only the group with the third-highest $\mathrm{pH}$ in Hunan lakes acidic. Nanchang, the capital of Jiangxi province, has become the center of the central China acid rain zone and acidification is spreading around the whole province because of the development of heavy industry and combustion of fossil fuel20. The industrial pollution then causes acid rain in some ways. Further research has proved that Jiangxi has suffered from the acidification of groundwater and surface lakes mainly because of acid rain 21 .

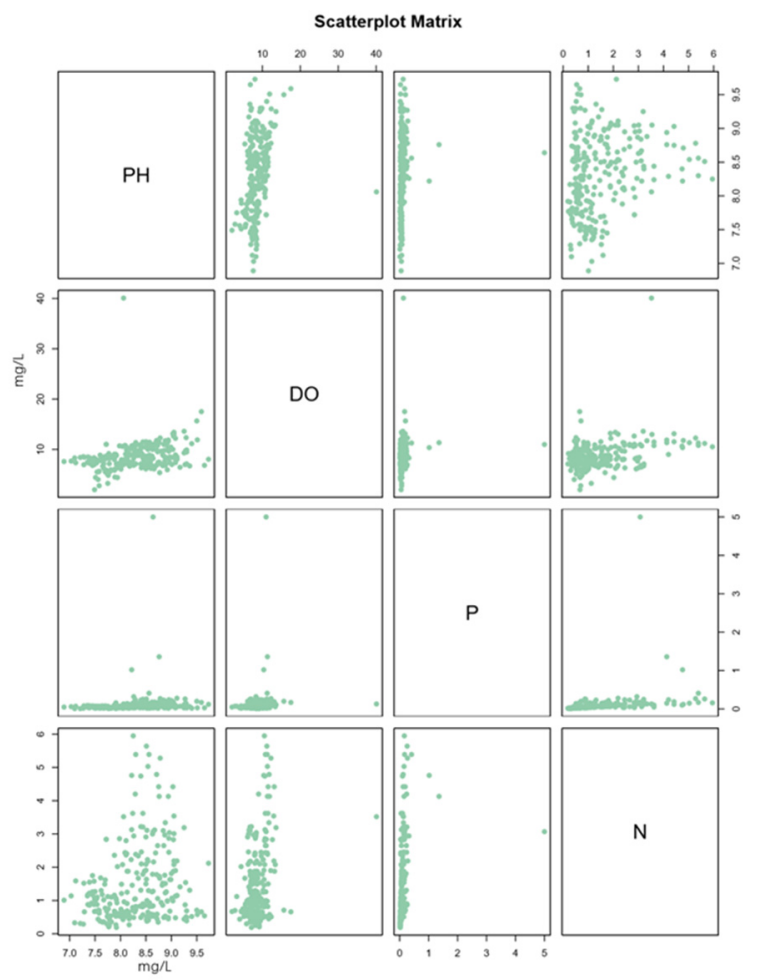

Fig. 6. The relationships between the five water quality indicators.

Figure 6 presents the relationship between the four measuring elements of lakes in the content of five provincial lakes. According to the figure, most of the relationships are not strong; they are either vertical, horizontal or scattered. However, according to additional regression test, the graph between $\mathrm{pH}$ and $\mathrm{DO}$ shows that $\mathrm{pH}$ is proportional to DO.

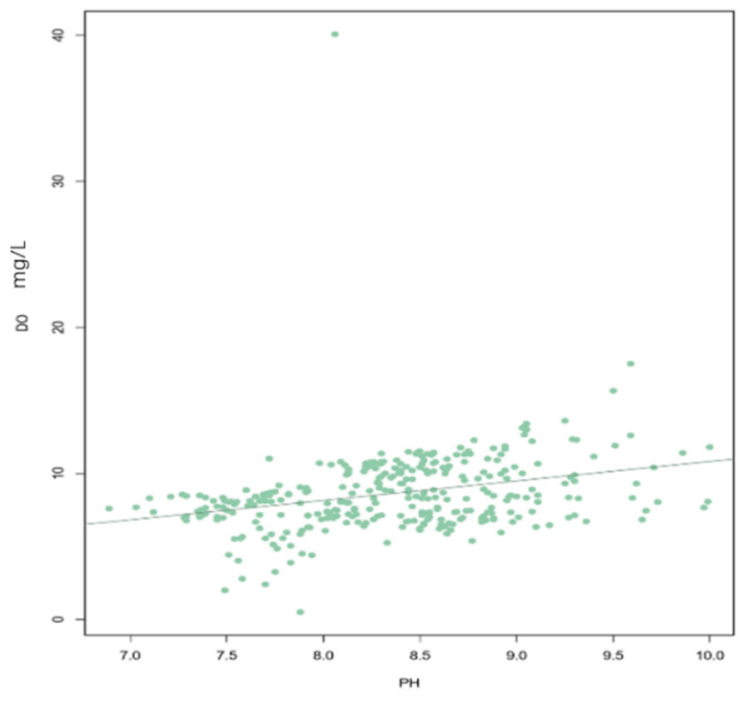

Fig. 7. The relationships between $\mathrm{pH}$ and $\mathrm{DO}$ in lakes of five provinces.

Figure7 presents the relationship between $\mathrm{pH}$ and DO in lakes of five provinces. The figure shows that they are proportional. As $\mathrm{pH}$ value of lakes increases, the dissolved oxygen content increases slowly and constantly. According to $\mathrm{t}$ test, the $\mathrm{p}$-value is $3.745 \mathrm{e}-08$ and this proves their proportional relationship. The specific regression equation is $\mathrm{DO}=1.33 \mathrm{PH}-2.51$.

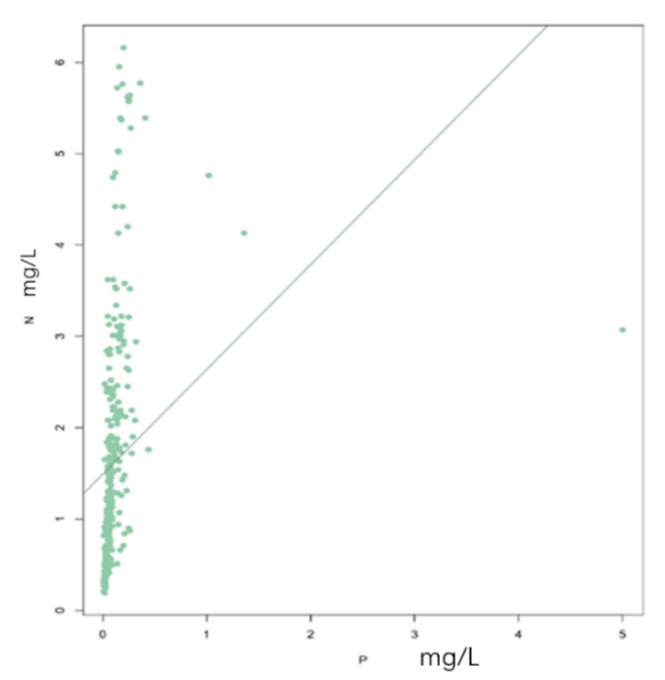

Fig. 8. The relationship between phosphorus and nitrogen content in lakes of five provinces.

Figure 8 presents the relationship between phosphorus and nitrogen content in lakes of five provinces. The nitrogen content increases very rapidly as $\mathrm{pH}$ value only increase at a rate that is below 0.5 . Additionally, the pvalue between them is $1.165 \mathrm{e}-06$ and proves that they have proportional relationship. To be specific, according to regression equation, the relationship satisfies with $\mathrm{P}=0.05 \mathrm{~N}+0.02$. 


\section{Conclusion}

Water has a great impact on human health, population growth, economic development, food production, and other important fields. For China, a rapidly but unevenly growing country of huge population and diverse geography, studying water quality issues can help governments, corporations, and the public become more aware of existing water pollution problems and solve them promptly. This study provides the most intuitive and effective information on the lake's water quality and possible sources of pollution by analyzing the four basic elements in the lake: nitrogen, phosphorus, $\mathrm{pH}$ value, and dissolved oxygen. Furthermore, the use of ANOVA test and regression equation to analyze water quality in five main typical developed provinces along the Yangtze river can be used to summarize and supplement the analysis of water quality in south China.

The study shows that Jiangsu's average dissolved oxygen content is the highest among the five provinces and is supposed to have the highest water quality because of the strong self-purification ability of water. However, since it also owns the most developed industry seen from data of the number of industrial enterprises and industrial wastewater. The result is that one of its famous cities, Wuxi, suffered blue-green algae bloom in 2007 because of excessive nitrogen and phosphorus mainly caused by the wastewater from the industrial sector. Anhui has low dissolved oxygen content which can harm the production in fishery because dissolved oxygen is the main source of oxygen for aquatic organisms. Chaohu lake, one of the biggest and most famous lakes in Anhui, has owned fewer fish of all types. The $\mathrm{pH}$ value of lakes in Jiangxi is much lower than that of lakes in other provinces. Jiangxi province suffers from acid rain all the year-round, which causes the acidification of groundwater and surface lakes.

There are some limitations to this study. The study's main data source - China scientific database - measures four elements in lakes in 2007 and 2008, which is also the most comprehensive database we could found. It means that all of the lakes in four provinces may be measured in either 2007 and 2008 instead of in the same year. Measurements of different lakes can vary by a few months. This may cause some comparison to be less temporally coherent. However, the measurement takes a lot of time and effort for different water quality indicators for many large lakes. The large coverage of the five provinces and the number of lakes make it more difficult or even impossible to measure all of the lakes at the same time and the same weather condition.

Finally, this study brings many insights into the area of water pollution analysis. During the research, it is difficult to obtain industrial and agricultural pollution data that can match the measurements of the four elements of water quality. As a result, the study can't directly point out whether the pollution element in the lake is caused by local industries and farms or other sources. Therefore, we suggest more research on the utilization of industrial wastewater and agricultural fertilizer. In the future, the analysis can be improved by linking the water quality with the wastewater from industrial and agriculture.

\section{References}

1. J. Xia.; L. Zhang.; Z. Hu. Situation and problem analysis of water resource security in China. Resources and Environment in the Yangtze Basin, 18 (2), 116.(2009)

2. J. Liu.; W. Yang. Water Sustainability for China and Beyond. Science (New York, N.Y.) 337, 649-650. https://doi.org/10.1126/science.1219471.(2012)

3. Y. Jiang. China's Water Scarcity. J. Environ. Manage. 90 (11), 3185-3196. https://doi.org/10.1016/j.jenvman.2009.04.016.(200 9)

4. S. Pan.; L. Cao.; J. Zhang. Water Quality Management in China: Situation, Problems and Challenges. Wat Res Prot, 21, 59-62.(2005)

5. B. Müller.; M. Berg.;Z. Yao.;X. Zhang.; D. Wang .; A. Pfluger. How Polluted Is the Yangtze River? Water Quality Downstream from the Three Gorges Dam. Science of The Total Environment, 402 (2), 232-247.

https://doi.org/10.1016/j.scitotenv.2008.04.049.(200 8)

6. X. Yu.; L. Wang.; Q. Yang.; S. Ye. Background of t he Yangtze River Economic Belt Development Strat egy and Geography Interpretation of Its Innovative Development. Progress in Geography, 34 (11), 1368 -1376. https://doi.org/10.18306/dlkxjz.2015.11.004. (2015)

7. J. Chen. Evolution and Water Resources Utilization of the Yangtze River; 2020.

8. China Lake Scientific Database; CAS.(2020)

9. R. Pelczar; M. Pelczar. Microbiology - Applied microbiology

https:/www.britannica.com/science/microbiology (2019)

10. S. Rounds.; F. Wilde.; G. Ritz. Chapter A6. Section 6.2. Dissolved Oxygen; 2006. https://doi.org/10.313 3/twri09A6.2.(2006)

11. B. Beers. What Regression Measures https://www.in vestopedia.com/terms/r/regression.asp. (2020)

12. Communique on the Results of the Second National Land Survey in Jiangsu Province; Jiangsu department of land and resources, 2014.

13. Communique on the Results of the Second National Land Survey in Anhui Province; Anhui department of land and resources, 2014.

14. Communique on the Results of the Second National Land Survey in Jiangxi Province; Jiangxi department of land and resources, 2014.

15. Communique on the Results of the Second National Land Survey in Hubei Province; Hubei department of land and resources, 2014.

16. Communique on the Results of the Second National Land Survey in Hunan Province; Hunan department of land and resources, 2014.

17. Guo, Longgen; Xie, Ping; Ni, Leiyi; Li,Hongyuan; $\mathrm{Hu}$,Wangming. Current Situation of Fishery 
Resources in Chaohu Lake and Its Response to Water Eutrophication. Acta Hydro Biologica sinica, 31 (5), 700-705.(2007)

18. CNKI. Overview of industrial economic development in provinces and cities http://tongji.cnki.net/kns55/addvalue/areaindusdevel op.aspx ? sicode $=Z 012$ \&areacode $=x j 10$ (2019).

19. G. Liang; H. He. Long struggle for a cleaner Lake Tai https://www.chinadialogue.net/article/show/single/e n/4767-Long-struggle-for-a-cleaner-Lake-Tai(2012).

20. J. Wu.; H. Zhou.; Z. He. Variation characteristics of acid rain in jiangxi and its relationship with meteorological condition. meteorology and disaster reduction research, 35 (02), 45-50.(2012)

21. M. Song.; L. Gong; P. Li.; T. Ma. Research Status of Partial Acid Groundwater in Xingguo County, Jiangxi Province. Acta Geoscientica Sinica, 39 (5), 581-586.(2018) 